$10-1-2013$

\title{
Evidence-based practice in occupational therapy curricula.
}

Tina Angelis, EdD, OTR/L

Department of Occupational Therapy, Jefferson School of Health Professions, Thomas Jefferson

University, Philadelphia, PA

Thomas G DiMarco

Thomas Jefferson University

Susan Toth-Cohen, EdD, OTR/L

Thomas Jefferson University

Follow this and additional works at: https://jdc.jefferson.edu/otfp

Part of the Occupational Therapy Commons

Let us know how access to this document benefits you

\section{Recommended Citation}

Angelis, EdD, OTR/L, Tina; DiMarco, Thomas G; and Toth-Cohen, EdD, OTR/L, Susan, "Evidencebased practice in occupational therapy curricula." (2013). Department of Occupational Therapy Faculty Papers. Paper 16.

https://jdc.jefferson.edu/otfp/16

This Article is brought to you for free and open access by the Jefferson Digital Commons. The Jefferson Digital Commons is a service of Thomas Jefferson University's Center for Teaching and Learning (CTL). The Commons is a showcase for Jefferson books and journals, peer-reviewed scholarly publications, unique historical collections from the University archives, and teaching tools. The Jefferson Digital Commons allows researchers and interested readers anywhere in the world to learn about and keep up to date with Jefferson scholarship. This article has been accepted for inclusion in Department of Occupational Therapy Faculty Papers by an authorized administrator of the Jefferson Digital Commons. For more information, please contact: JeffersonDigitalCommons@jefferson.edu. 


\author{
As submitted to: \\ Occupational Therapy in Health Care \\ And later published as: \\ Evidence Based Practice in Occupational Therapy Curricula \\ Volume 27, Issue 4, October 13, page: 323-32 \\ DOI: $10.3109 / 07380577.2013 .843115$ \\ Tina M. DeAngelis, Thomas G. DiMarco, Susan Toth-Cohen \\ Thomas Jefferson University, Philadelphia, PA, USA
}

\begin{abstract}
The purpose of this study is to describe currently used educational strategies for teaching evidence-based practice (EBP) in entry-level master's degree occupational therapy programs in the United States. Fifty-eight entry level occupational therapy program directors completed a survey. Results showed occupational therapy programs consistently use a wide variety of EBP resources for teaching EBP including database searches, literature reviews, and the development of a research proposal. Less commonly used strategies include the use of case stories and journal clubs. The current study provides a baseline of current strategies taught in entry level programs that may be built upon to gather more information about the content of EBP coursework, and determine ways to foster implementation of EBP in practice.
\end{abstract}

KEYWORDS. Evidence-based practice, education, teaching, program director, occupational therapy, curricula.

The specific teaching of content related to evidence-based practice has become an integral part of $21^{\text {st }}$ Century occupational therapy curricula as mandated by the Accreditation 
Council on Occupational Therapy Education standards (AOTA, 2012). Evidence-based practice terminology is also an integral constituent of the American Occupational Therapy Association's Centennial Vision (AOTA, 2006). The Centennial Vision (CV) was developed to outline a strategic set of goals for the occupational therapy profession to accomplish by its 100th year anniversary in 2017, including the profession being "evidence-based" (AOTA, 2006, para 1). In related literature, Thomas and Javerherian (2008) called on occupational therapy educators to heed the call of the CV, and Van Lew and Singh (2010) stated that to accomplish the goals of the $\mathrm{CV}$, the profession needs academic as well as clinical evidence-based practice learning (Van Lew \& Singh, 2010).

Literature published in the field of occupational therapy has supported the need to apply EBP to clinical settings (McCluskey \& Cusick, 2002; Rappolt, 2003; Ilott, 2003; Lee \& Miller, 2003; Lin, Murphy, \& Robinson, 2010) and identify the techniques utilized to teach occupational therapy students (future practitioners) to become evidence-based in their practice (TickleDegnen, 2000; Silverman, 2010). However, little is known about the specifics of what is being presently taught in entry-level curricula nationwide related to EBP. For example, a review of guiding documents from the American Occupational Therapy Association (see Table 1) as well as the ACOTE Standards (2012) reveals that although the importance of EBP is apparent and in some cases mandated, little guidance is provided as to the specific content to include in occupational therapy curricula.

A review of the occupational therapy EBP literature from 2000 to 2010 clearly demonstrates that the occupational therapy profession has strived to teach EBP strategies and their significance to therapists and students (see Tables 2 and 3). In order to provide the best client care however, it is important for students to be fully prepared and aware of how to adhere 
to and apply these strategies when they begin their careers as evidence-based occupational therapy practitioners. Although some studies have described specific methods of teaching EBP to students, no published reports have comprehensively identified the specific strategies that entry level occupational therapy programs in the U. S. currently use to teach EBP. This limited information suggests a significant gap in understanding if occupational therapy students are learning what the profession expects in order for them to become evidence-based practitioners. A first step in teaching students correctly is to determine what is being taught in occupational therapy curricula today. This knowledge can then be used as a springboard for further research within occupational therapy curricula, to ascertain how students are instructed to be cognizant of and adhere to the tenets of evidence-based occupational therapy practice. This present survey will provide data that can help to fill this gap.

\section{METHODS}

\section{Sample}

This survey used a purposive sample of accredited occupational therapy entry-level program directors across the U.S, accessed from program listings on the AOTA website page at: http://www.aota.org/Students/Schools/EntryLevelOT/38119.aspx . Post-professional occupational therapy programs and entry level occupational therapy assistant and doctoral programs were not included. Of the 141 programs contacted, 58 completed the survey, which is a response rate of $41 \%$.

\section{Instrumentation}


The survey questions (Appendix) were created from a review of literature related to EBP educational strategies including articles detailing course and course components and student experiences with EBP, as well as AOTA guiding documents (Table 1). In addition a selected review of entry-level occupational therapy program websites provided additional insight into question construction. Question content focused on: the types of courses used to deliver EBP concepts; the total number of EBP courses in the curriculum; the types of EBP tools used; resources and techniques utilized to develop and teach EBP concepts and evaluate instruction of EBP; objectives for teaching EBP; steps of the EBP process; approaches used to support EBP curriculum to the Centennial Vision; and the use of dedicated EBP only courses. The survey was reviewed by peers and edited based on their feedback.

\section{Procedures}

The online survey was conducted using Survey Monkey (www.surveymonkey.com). Recruitment letters were emailed directly from the Survey Monkey website with a link to the survey. The initial email contact was followed by two reminder emails.

\section{Data Analysis}

Descriptive statistics were used to calculate the frequency of responses for each question. Percentages for each answer choice were reviewed, and answers for different questions were compared to each other. The main results are discussed below.

\section{RESULTS}

Of the 58 programs that responded to the survey, $48(83 \%)$ reported that they incorporate EBP concepts in at least 7 courses, $22(38 \%)$ reported including EBP concepts in 10 or more 
courses, and $12(21 \%)$ reported including EBP in all courses. Fifty-six programs (97\%) reported incorporating EBP concepts in clinical skills/clinical intervention courses, 55 programs (95\%) in research courses, and 53 programs (91\%) in assessment/evaluation courses. EBP concepts were taught in level I fieldwork courses in only 35 programs (60\%), and in level II fieldwork courses in only 39 programs (67\%). A course that focuses exclusively on EBP was reported in 31 programs $(53 \%)$.

As summarized in figure 1, a majority of programs used common strategies for teaching EBP concepts, with less programs utilizing case stories (31 or 53\%) and journal clubs (17 or 29\%). Resources used by programs for developing and teaching EBP concepts varied as well. Every program reported that they used AOTA's evidence resources. Other resources used included OT CATS (45 programs or 78\%), OT Practice Framework: Domain and Process II (45 programs or $78 \%$ ), ACOTE Standards (44 programs or $76 \%$ ) and The Cochrane Collaboration (50 programs or $86 \%$ ). A lower number of programs used the OT Model Curriculum (11 programs or 19\%) and the Blueprint for Entry Level Education (16 programs or 28\%).

Resources used for evaluating the instruction of evidence-based concepts garnered different responses. The number of programs that responded to this question was 51. Almost all programs used the ACOTE standards to guide the evaluation of the teaching of EBP (48 out of 51 or $94 \%$ ). Besides this, no other resource was used by more than 28 out of 51 programs or 55 percent. For example the percentage drops to $14 \%$ ( 7 of 51 programs) for World Federation of occupational therapists (WFOT) resources and 20\% (10 of 51 programs) for World Health Organization (WHO) resources. For another question, 100\% of program directors (58) identified enabling students to choose effective assessment and intervention strategies as a primary objective for teaching EBP concepts in their curriculum, while a slightly lower percentage 
believe that enabling students to communicate the effectiveness of occupational therapy to other healthcare professionals (90\% or 52 programs) and to consumers (93\% or 54 programs) is a primary objective.

Regarding the six steps of evidence-based practice discussed by Lin et al. (2010), results showed that the first four steps are taught to students in a range from 97 to $100 \%$ of the programs (56 to 58 programs), but the last two steps, evaluate one's performance or outcomes and communicate knowledge to other health and human service professionals are taught in a lower percentage of programs ( 79 and $86 \%$ or 46 and 50 programs respectively). As shown in figure 2, the use of different approaches by occupational therapy programs to work towards the goal of the profession becoming evidence-based as outlined in the Centennial Vision ranged from 86 to $98 \%$ (50 to 57 programs respectively).

\section{DISCUSSION}

This study showed the profession of occupational therapy is making the teaching of EBP principles a priority in education. This is clearly demonstrated by the response to the survey question as to whether EBP is a core thread in their curriculum: $85 \%$ of program directors answered in the affirmative. The fact that over half the programs include a course dedicated to teaching EBP to students, that a majority of programs infuse EBP concepts in most if not all of their courses, that almost $90 \%$ of programs teach students how to develop a research proposal, and that more than $90 \%$ teach the first four steps of the EBP process to students, indicates an alignment with guiding principles set forth by the profession related to EBP. Also, since the AOTA and other organizations have developed resources related to EBP, the use these of resources for developing and teaching EBP as well as for evaluating the instruction of EBP is an 
indication that the occupational therapy education community has been utilizing what has been made available by the profession related to the instruction of EBP.

However, although these data suggest that while students are learning about EBP and its core principles, there are potential areas for improvement that should be considered. For example, almost half the programs did not have a course dedicated solely to teaching only EBP. This type of course was recommended early on by Tickle-Degnen (2000), who discussed how she transformed a research course into an EBP course in order to teach students more effectively, so there is an impetus for creating this type of course. A program that does not have a dedicated EBP only course and decides to follow this this recommendation can create or modify a course to be used strictly for EBP. This may result in more effective EBP education, as Tickle-Degnen (2000) asserted.

Other areas can be addressed as well. Bailey et al. (2007) were able to translate knowledge learned by the use of a case story in a post-professional occupational therapy course into clinical practice months after the course ended. The positive influence of the use of case stories such as in this example may be repeated by including these in EBP coursework if they are not present in a program. Similarly, the benefits of the use of journal clubs for EBP was shown by Stern (2008) who explained that students became more dedicated in the use of evidence in practice after a nine week experience with journal clubs. Adding these to EBP coursework if they are not already part of the curriculum may yield similar positive results. Likewise, including the final two steps of EBP as outlined by Lin et al. (2010) when teaching EBP concepts to students, if these steps are not being taught currently, would be an easy way to include more knowledge for student learning. 
The Occupational Therapy Model Curriculum includes many recommendations related to using EBP in curricula (Berg et al., 2009). This and other similar documents that include guidelines for EBP are a potential source of beneficial information for occupational therapy programs. Investigating the applicability of these resources is one way for programs to start utilizing more varied resources to develop and teach EBP or to evaluate the instruction of EBP. An article by Reynolds (2010) discusses an online doctorate level EBP course where students are trained in the use of databases and library services, as well as in the use of article citation software. If an occupational therapy program does not currently use database tutorials, making these available to students who have access to databases and need the help, may result in similar positive experiences for students.

A potential issue noted is that although $93 \%$ of programs state that students learn to apply interventions from an evidence-based perspective, and over $95 \%$ of clinical skills/clinical intervention courses include EBP concepts, only 6 in 10 programs incorporate EBP concepts in level I fieldwork courses, and only two-thirds include EBP concepts in level II fieldwork. Since fieldwork settings are most students' first exposure to actual clinical interventions with clients, it should be expected that EBP concepts would be incorporated more in fieldwork but it does not seem to be the case, at least for this sample.

A lower presence of the teaching or implementation of EBP principles in fieldwork may be related to a facility's lack of EBP capabilities which can manifest in a number of different ways including those outlined in a study by Dysart and Tomlin (2002), such as a lack of resources, clinician ability, time, or support from those in charge. Bennett et al. (2003) found similar barriers to EBP in their study. In order to address these barriers, schools can use innovative techniques such as EBP learning modules during fieldwork like those described by 
Van Lew and Singh (2010), which clearly articulate important knowledge milestones to reach during fieldwork such as an overview of assistive technology that a student will likely encounter during an internship. Students may also benefit from the use of discussion boards to reflect on their experiences and integrate knowledge from their academic program into practice, a strategy used in a dedicated EBP course during fieldwork at the Jefferson School of Health Professions, Thomas Jefferson University (Vause-Earland, personal communication, May 23, 2012). Other techniques can be used to help students use EBP during fieldwork such as timed literature searches and the use of a notebook for EBP which allows students to have a resource which they can refer back to regularly, as outlined by Coster and Schwarz (2004). The authors assert that the limited presence of EBP in fieldwork suggests a potential threat to the sustainability of EBP outside of academia that could impede the profession's achievement of the Centennial Vision as an evidence-based, science-driven profession.

\section{SUMMARY}

Occupational therapy has made progress in realizing the mandate for the profession to embrace evidence-based practice, which includes the teaching of this to students, as outlined by the Centennial Vision (AOTA, 2006). The present study adds to the existing knowledge base on EBP in occupational therapy curricula by identifying current formats, resources and strategies used to teach EBP concepts. Future studies could expand on this by identifying more detail related to EBP content, determining specifically how EBP is integrated in individual courses and throughout the curriculum in occupational therapy programs including post entry level programs, comparing demographic information to EBP in curriculum to look for trends, and learning faculty perceptions of EBP content in occupational therapy curriculum. In addition, other areas for potential future research include evaluating the effectiveness of these strategies on student's 
ability to integrate into fieldwork and catalyze a change in field work, perhaps to include 5 and 10 year outcomes of students' use of evidence.

\section{REFERENCES}

Aitken, M. (2004). Meta-analysis for the educator and practitioner. Education Special Interest Section Quarterly, 14(4), 1-4.

American Occupational Therapy Association (2006). AOTA's Centennial Vision. [Electronic version]. Retrieved from: http://www.aota.org/News/Centennial/Background/ 36516.aspx

American Occupational Therapy Association. (2008). Occupational therapy practice framework: Domain and process (2nd ed.). American Journal of Occupational Therapy, 62, 625-683. American Occupational Therapy Association (2012). 2011 Accreditation Council for Occupational Therapy Education (ACOTE) Standards and Interpretive Guide. [Electronic version] Retrieved from: http://www.aota.org/Educate/Accredit/DraftStandards/50146.aspx?FT=.pdf

Atler, K. \& Gavin, W. J. (2010). Service-learning-based instruction enhances students' perceptions of their abilities to engage in evidence-based practice. Occupational Therapy in Health Care, 24(1), 23-38. 
Bailey, D. M., Bornstein, J., \& Ryan, S. (2007). A case report of evidence-based practice: From academia to clinic. American Journal of Occupational Therapy, 61, 85-91.

Bennett, S., Tooth, L., McKenna, K., Rodger, S., Strong, J., Ziviani, J., Mickan, S., \& Gibson, L., (2003). Perceptions of evidence-based practice: A survey of Australian occupational therapists. Australian Occupational Therapy Journal, 50, 13-22.

Berg, C., Black, R., Fazio, L., Finlayson, M., Hooper, B., Krishnagiri, S., Padilla, R., Rapp, C. Q., Harvison, N., \& Rotert, D. (2009). Occupational therapy model curriculum. [Electronic version]. Retrieved from: http://www.aota.org/Educate/EdRes/ COE/OtherEducation-Documents/OT-Model-Curriculum.aspx

Coster, W., \& Schwarz, L. (2004). Facilitating transfer of evidence-based practice into practice. Education Special Interest Section Quarterly, 14(2), 1-3.

Crist, P. A. (2010). Adapting research instruction to support the scholarship of practice: Practicescholar partnerships. Occupational Therapy in Health Care, 24(1), 39-55.

DeLany, J. V., Amini, D., Cohn, E., Cruz, J., Hartmann, K., Justice, J., Kannenberg, K., Lew, C., Marc-Aurele, J., Youngstrom, M.J., \& Lieberman, D. (2010). Standards of practice for occupational therapy. American Journal of Occupational Therapy, 64, 415-420.

Dysart, A. M., \& Tomlin, G. S. (2002). Factors related to evidence-based practice among U.S. occupational therapy clinicians. American Journal of Occupational Therapy, 56, 275284.

Haynes, D. A., Jones, T., \& Fazio, L. S. (2007). Philosophy of occupational therapy education. American Journal of Occupational Therapy, 61, 678.

Holm, M. B. (2000). Our mandate for the new millennium: Evidence-based practice, 2000 Eleanor Clarke Slagle lecture. American Journal of Occupational Therapy, 54, 575-585. 
Ilott, I. (2003). Challenging the rhetoric and reality: Only an individual and systemic approach will work for evidence-based occupational therapy. American Journal of Occupational Therapy, 57, 351-354.

Law, M., \& Baum, C. (1998). Evidence-based occupational therapy. Canadian Journal of Occupational Therapy, 65, 131-135.

Lee, C.J., \& Miller, L. T. (2003). The process of evidence-based clinical decision making in occupational therapy. American Journal of Occupational Therapy, 57, 473-477.

Lin, S. H., Murphy, S. L., \& Robinson, J. C. (2010). The Issue Is-Facilitating evidence-based practice: Process, strategies, and resources. American Journal of Occupational Therapy, 64, 164-171.

Martin, L. M. (2000). Teaching research to undergraduates. Education Special Interest Section Quarterly, 10(4), 2-3.

McCluskey, A., \& Cusick, A. (2002). Strategies for introducing evidence-based practice and changing clinician behaviour: A manager's toolbox. Australian Occupational Therapy Journal, 49, 63-70.

Muir-Gray, M (2009). Evidence-based healthcare and public health ( $3^{\text {rd }}$ ed.). United Kingdom: Churchill Livingstone/Elsevier Limited.

Padilla, R., Bilics, A., Blum, J. C., Bohr, P. C., Coyne, J. C., Gupta, J, Musselman, L., Orr, L., Sipp, A., Stutz-Tanenbaum, P., \& Harvison, N. (2009). Specialized knowledge and skills of occupational therapy educators of the future. American Journal of Occupational Therapy, 63, 804-818.

Rappolt, S. (2003). The role of professional expertise in evidence-based occupational therapy. American Journal of Occupational Therapy, 57, 589-593. 
Reynolds,S. (2010) Teaching evidence-based practice in a distance education occupational therapy doctoral program: Strategies for professional growth and advancing the profession. Occupational Therapy in Health Care, 24(1), 56-67.

Schell, B. A., Cevero, R., Currie, M. K., Davis, J., Roberts, P., Schultz-Krohn, W., Urish, C., \& Louch, M. E. (2010). Standards for continuing competence. American Journal of Occupational Therapy, 64, 411-413.

Silverman, F. (2010). Teaching qualitative research methods using a simulation exercise. Education Special Interest Section Quarterly, 20(2), 1-4.

Stern, P. (2001). Occupational therapists and research: Lessons learned from a qualitative research course. American Journal of Occupational Therapy, 55, 102-105.

Stern, P. (2005). A holistic approach to teaching evidence-based practice. American Journal of Occupational Therapy, 59, 157-164.

Stern, P. (2008). Using journal clubs to promote skills for evidence-based practice. Occupational Therapy in Health Care, 22(4), 36-53.

Stube, J. E., \& Jedlicka, J. S. (2007). The acquisition and integration of evidence-based practice concepts by occupational therapy students. American Journal of Occupational Therapy, $61,53-61$.

Thomas, H. \& Javaherian, H. (2008). The centennial vision and the education special interest section. Education Special Interest Section Quarterly, 18(1), 2-4.

Tickle-Degnen, L. (2000). Teaching evidence-based practice. American Journal of Occupational Therapy, 54, 559-560.

Van Lew, S., \& Singh, N. (2010). Integrating the Centennial Vision into an evidence-based fieldwork-learning experience. Occupational Therapy in Health Care, 24(1), 68-73. 


\section{Appendix}

\section{Survey Questions}

1. Instructions for the survey: Completion of the following brief survey will assist us as we continue to understand the strategies currently utilized to teach evidence-based practice (EBP) in occupational therapy curricula in the United States. Please answer all uestions as completely as possible. Taking the survey indicates your consent to participate. Thank you.

Yes, I understand these instructions

No, I do not understand these instructions

2. Please provide an estimate of how many courses in your program's OT curriculum incorporate evidencebased practice (EBP) concepts?

0

$1-3$

4-6

7-9

10 or more

All

Other (please specify

3. Are there any courses in your curriculum that focus exclusively on EBP?

Yes

No

Other (please specify

4. Please check all the types of courses within your curriculum that include evidence based practice (EBP) concepts:

Assessment/Evaluation

Clinical skills/Clinical intervention

Foundational knowledge (anatomy, neuroanatomy, occupation)

Level I fieldwork

Level II fieldwork

Master's projects/courses

Research

Theory

Other (please specify

5. Please check all evidence-based practice (EBP) related tools used to teach occupational therapy students in your curriculum:

Development of PICO questions

Critically appraised topics (CAT) 
Critically appraised papers (CAP)

Abstract reviews

Journal clubs

Database tutorials

Case stories

Literature review

Quantitative analysis exercises

Qualitative analysis exercises

Database searches

Levels of evidence hierarchies

Development of a research proposal (research question, relevant literature, sample, design, measurement $\&$ data analysis)

Other (please specify

6. Please check all resource(s) used for developing and teaching evidence-based practice (EBP) concepts in your curriculum:

ACOTE (Accreditation Council for Occupational Therapy Education) standards American Occupational Therapy Association evidence resources

American Occupational Therapy Association's Centennial Vision

Blueprint for Entry-Level Education

Occupational Therapy Practice Framework II

Standards of Continuing Competence (AOTA)

Occupational Therapy Code of Ethics (AOTA)

OT Model Curriculum (AOTA)

Standards of Practice in OT (AOTA)

Philosophy of OT Education (AOTA)

The Cochrane Collaboration (Website, Library, Resources)

OT Seeker

OTCATS (Occupational Therapy Critically Appraised Topics

World Federation of OT (WFOT) resources

World Health Organization (WHO) resources

International Classification of Functioning, Disability and Health (ICF)

Other (please specify

7. Please check all resource(s) used for evaluating instruction of evidence-based concepts in your curriculum:

ACOTE (Accreditation Council for Occupational Therapy Education) standards

American Occupational Therapy Association evidence resources

Occupational Therapy Practice Framework II

Standards of Continuing Competence (AOTA)

Occupational Therapy Code of Ethics (AOTA)

OT Model Curriculum (AOTA)

Standards of Practice in OT (AOTA)

Philosophy of OT Education (AOTA)

The Cochrane Collaboration (Website, Library, Database)

World Federation of OT (WFOT) resources

World Health Organization (WHO) resources

International Classification of Functioning, Disability and Health (ICF) 
Other (please specify

8. In your opinion, the primary objectives for teaching evidence-based practice concepts in occupational therapy curricula are to enable students to: (check all that apply)

Choose effective assessment and intervention strategies

Develop systematic clinical reasoning processes

Improve credibility of the profession of occupational therapy

Communicate the effectiveness of OT to other healthcare professionals

Communicate the effectiveness of OT to consumers

Expedite knowledge translation from research to practice

Other (please specify)

9. Which of the following steps of evidence based practice are taught in your curriculum? (check all that apply):

Formulate the clinical question

Search efficiently for the best available evidence

Critically analyze evidence for validity and usefulness

Integrate best evidence with clinical expertise and client preferences

Evaluate one's performance or outcomes

Communicate knowledge to other health and human service professionals

Other (please specify

10. AOTA's Centennial Vision aspires for occupational therapy to be an "evidence-based" profession by the year 2017. How does your curriculum support this aspect of the Centennial Vision? (please check all that apply):

The mission and vision of the program includes a focus on evidence based practice

Evidence-based practice is a core thread in the curriculum

Library resources provide support for students to develop skills in evidence based practice

Students learn to apply interventions from an evidence based perspective

Both quantitative and qualitative research are recognized as contributing to evidence based practice

Other (please specify

11. Please utilize this space for any comments. Thank you for your participation! 
